\title{
Evaluation of Hepatic Resection in Liver Metastasis of Gastric Cancer
}

\author{
Yukiko Nonaka $^{1}$ (D) Kazuhiro Hiramatsu ${ }^{1} \cdot$ Takehito Kato $^{1} \cdot$ Yoshihisa Shibata ${ }^{1} \cdot$ Motoi Yoshihara $^{1} \cdot$ Taro Aoba $^{1}$. \\ Tadahiro Kamiya $^{1}$
}

Received: 21 April 2018 / Accepted: 13 November 2018 / Published online: 22 November 2018

(C) The Author(s) 2018

\begin{abstract}
Gastric cancer is the second most common malignancy globally and the third most common cause of cancer-related deaths in Japan. In gastric cancer, benefit of surgical resection of liver metastasis, which was shown in colorectal cancer, is not well established. The present study aimed to examine the feasibility of hepatic resection for liver metastasis of gastric cancer. In this retrospective study, we reviewed the medical records of 10 patients with liver-only metastases of gastric cancer who underwent hepatectomy among 2043 patients with gastric cancer who underwent gastric resection between January and December 2016 at a single institution in Japan. Median 1-, 3-, and 5-year overall survival (OS) rates were $78.0 \%, 33.3 \%$, and $22.2 \%$, respectively, among 10 patients who underwent hepatic resection. There was a significant difference in OS rates between tumors measuring $\geq 5 \mathrm{~cm}$ and $<5 \mathrm{~cm}$ (hazard ratio [HR] $6.524,95 \%$ confidence interval [CI] 1.145-37.171, $p=0.035$ ). The longest survival was 205 months for one patient who was alive at the time of the analysis. Hepatic resection of liver metastasis in gastric cancer was associated with long-term survival in some patients. Additionally, primary tumor size was associated with long-term survival.
\end{abstract}

Keywords Gastric cancer $\cdot$ Liver surgery $\cdot$ Liver metastasis $\cdot$ Management of metastasis

\section{Introduction}

Gastric cancer is the second most common malignancy globally and the third most common cause of cancerrelated deaths in Japan. Despite considerable advances in overall gastric cancer treatment, approaches for the treatment of gastric cancer metastasizing only to the liver have been controversial. Some studies suggest that hepatectomy is effective against gastric cancer with only liver metastasis, with a 5-year overall survival (OS) ranging from 20 to $40 \%$ [1-11], whereas results of other studies investigating the benefit of hepatic resection for liver metastasis of gastric cancer were unclear [12-14]. The present study aimed to evaluate the

Yukiko Nonaka

yukinohini@hotmail.com

1 Department of General Surgery, Toyohashi Municipal Hospital, 50 Aza Hachiken Nishi, Aotake-Cho, Toyohashi, Aichi 441-8570, Japan outcomes of surgical treatment for liver metastasis of gastric cancer.

\section{Materials and Methods}

In this retrospective study, we reviewed the medical records of 10 patients with liver-only metastases of gastric cancer who underwent hepatic resection among 2043 patients with gastric cancer who underwent gastric resection between January and to December 2016 at Toyohashi Municipal Hospital. The study flowchart is presented in Fig. 1.

Inclusion criteria for this study were as follows: (1) histologically confirmed gastric cancer; (2) presence of synchronous or metachronous liver metastasis; and (3) surgical therapy performed between January 1, 1991, and December 31, 2017. Patients with double cancers were excluded. The study was conducted in accordance with the Declaration of Helsinki of 1975, revised in 2000. Clinical and pathological data included sex, age, and information regarding primary gastric cancer and liver metastases. The 14th edition of the Japanese 
Classification of Gastric Carcinoma was utilized for this study. Data regarding the last follow-up and vital status were collected for all the patients.

\section{Statistical Analysis}

Univariate analysis was performed using Cox proportional hazards regression to identify the risk factors that were associated with OS and recurrence-free survival (RFS). All data were analyzed using the Statistical Package for Social Science software version 21.0 (SPSS, Chicago, IL, USA). For all analyses, $p<0.05$ was considered to be statistically significant.

\section{Results}

\section{Patient Characteristics}

Patient characteristics are presented in Tables 1 and 2. In total, 10 patients, including nine males and one female, underwent hepatectomy for liver metastasis of gastric cancer. Synchronous and metachronous metastases were noted in four $(40.0 \%)$ and six $(60.0 \%)$ patients, respectively, whereas single and multiple liver metastases were found in seven $(70.0 \%)$ and three $(30.0 \%)$ patients, respectively. Tumor size was > $3 \mathrm{~cm}$ in four (40.0\%) patients, and two patients $(20.0 \%)$ had new liver metastases after hepatic resection and underwent second hepatic resection.

\section{Patient Outcomes}

Median age at the time of hepatic resection was 68 (range, 4775) years. Patient outcomes are presented in Table 3. Briefly, $1-, 3-$, and 5-year OS rates after surgery were $78.0 \%, 33.3 \%$, and $22.2 \%$, respectively, with a median OS of 2.583 years.

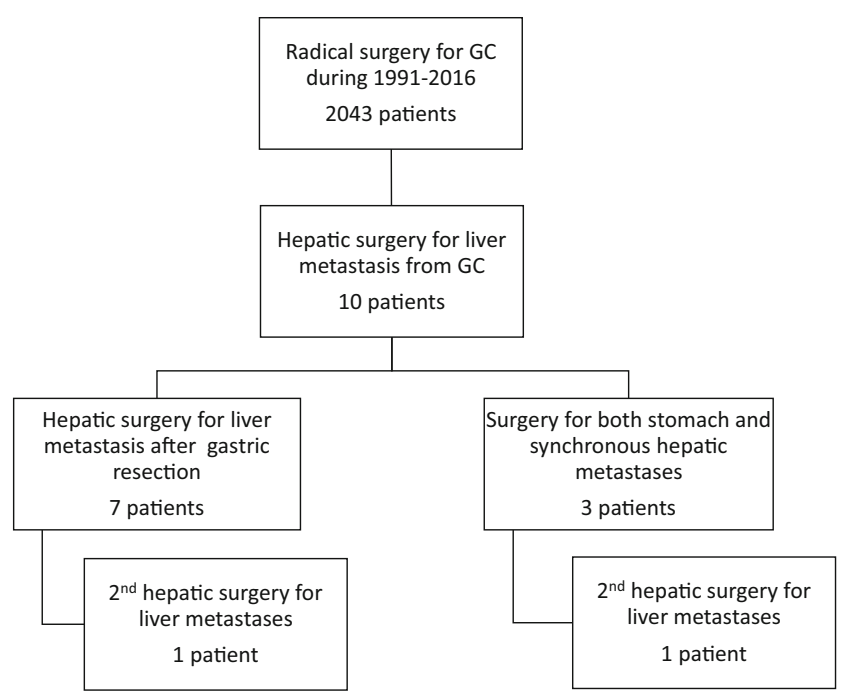

Fig. 1 Flow chart
Table 1 Characteristics

\begin{tabular}{ll}
\hline Variable & Value \\
\hline Age & \\
Median (range) & $68(47-75)$ years \\
Sex & \\
Male & $9(90.0 \%)$ \\
Female & $1(10.0 \%)$ \\
Tumor size & \\
$<5$ cm & $6(60.0 \%)$ \\
$\geqq 5$ cm & $4(40.0 \%)$ \\
Histological type & \\
Intestinal & $6(60.0 \%)$ \\
Diffuse & $4(40.0 \%)$ \\
Lymphatic invasion & \\
ly 0 & $2(20.0 \%)$ \\
ly $1 / 2 / 3$ & $8(80.0 \%)$ \\
Tumor invasion & \\
T0/T1 & $1(10.0 \%)$ \\
T2 SS & $2(20.0 \%)$ \\
T3 SE T4 SI & $7(70.0 \%)$ \\
Lymph node metastasis & \\
N0 + N1 & \\
N2 + N3 & $7(70.0 \%)$ \\
Metachronous/Synchronous & $3(30.0 \%)$ \\
Metachronous $6(60.0 \%)$ & \\
Synchronous $4(40.0 \%)$ & \\
Number of metastasis & \\
1 & \\
2 & \\
Number of hepatic surgery & \\
Once & \\
Twice 2 & \\
\hline & \\
\hline & \\
\hline
\end{tabular}

Additionally, 1-, 3-, and 5-year RFS rates were 44.4\%, 22.2\%, and $22.2 \%$, respectively, with a median RFS of 0.792 years.

There was a significant difference in OS between patients whose primary gastric cancer measured $\geq 5 \mathrm{~cm}$ and those whose primary gastric cancer measured $<5 \mathrm{~cm}$ (hazard ratio [HR] 6.524, 95\% confidence interval [CI] 1.145-37.171, $p=$ 0.035 ). There was a trend towards a difference in OS rates between patients whose cancer depth was serosal exposure (SE) or serosal invasion (SI) and those whose cancer depth was shallower than SE (HR 4.288, 95\% CI 0.849-21.661, $p=$ 0.078).

\section{Discussion}

Despite improved postoperative outcomes in recent years [15], survival rates of patients with liver metastasis of gastric 


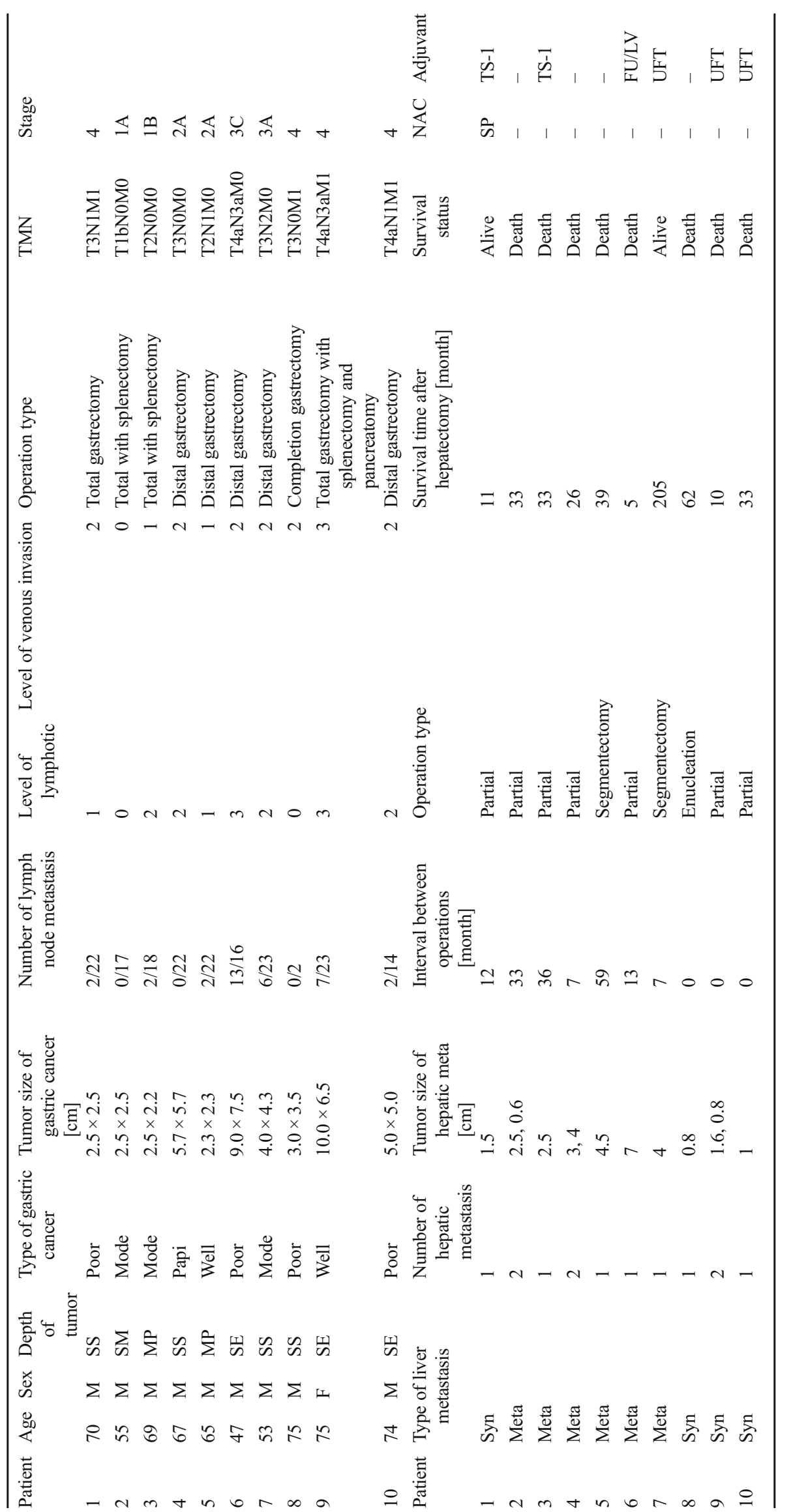


Table 3 Univariate analysis

\begin{tabular}{|c|c|c|c|c|c|c|c|}
\hline \multicolumn{8}{|c|}{ Univariate analysis of hazard ratio estimated by Cox regression (OS/RFS) } \\
\hline & Number & HR & $95 \% \mathrm{CI}$ & $p$ & HR & $95 \% \mathrm{CI}$ & $p$ \\
\hline \multicolumn{8}{|l|}{ Sex } \\
\hline Female & 1 & 1 & & & 1 & & \\
\hline Male & 9 & 0.118 & $0.007-1.886$ & 0.131 & 0.407 & $0.042-3.931$ & 0.437 \\
\hline \multicolumn{8}{|l|}{ Age years } \\
\hline$<65$ & 3 & 1 & & & 1 & & \\
\hline$\geqq 65$ & 7 & 1.493 & $0.296-7.529$ & 0.628 & 1.345 & $0.264-6.854$ & 0.721 \\
\hline \multicolumn{8}{|c|}{ Tumor size of primary cancer } \\
\hline$<5 \mathrm{~cm}$ & 6 & 1 & & & 1 & & \\
\hline$\geqq 5 \mathrm{~cm}$ & 4 & 6.524 & $1.145-37.171$ & 0.035 & 3.216 & $0.706-14.649$ & 0.131 \\
\hline \multicolumn{8}{|c|}{ Histological type } \\
\hline Intestinal & 6 & 1 & & & 1 & & \\
\hline Diffuse & 4 & 1.084 & $0.256-4.592$ & 0.913 & 0.794 & $0.188-3.356$ & 0.754 \\
\hline \multicolumn{8}{|c|}{ Lymphatic invasion } \\
\hline ly0/ly1 & 4 & 1 & & & 1 & & \\
\hline ly $2 /$ ly 3 & 6 & 1.636 & $0.384-6.962$ & 0.505 & 1.692 & $0.401-7.149$ & 0.474 \\
\hline \multicolumn{8}{|l|}{ Venous invasion } \\
\hline V0/V1 & 3 & 1 & & & 1 & & \\
\hline $\mathrm{V} 2 / \mathrm{V} 3$ & 7 & 0.939 & $0.206-4.288$ & 0.935 & 0.555 & $0.123-3.507$ & 0.444 \\
\hline \multicolumn{8}{|l|}{ Tumor invasion } \\
\hline $\mathrm{T} 0 / \mathrm{T} 1 / \mathrm{T} 2$ & 3 & 1 & & & 1 & & \\
\hline $\mathrm{T} 3 / \mathrm{T} 4$ & 7 & 4.288 & $0.849-21.661$ & 0.078 & 2.248 & $0.500-10.097$ & 0.291 \\
\hline \multicolumn{8}{|c|}{ Lymph node metastasis } \\
\hline No & 4 & 1 & & & 1 & & \\
\hline $\mathrm{N} 1 / \mathrm{N} 2 / \mathrm{N} 3$ & 6 & 0.88 & $0.217-3.566$ & 0.858 & 0.559 & $0.136-2.292$ & 0.419 \\
\hline \multicolumn{8}{|c|}{ Metachronous/synchronous } \\
\hline Metachronous & 6 & & & & 1 & & \\
\hline Synchronous & 4 & 0.98 & $0.231-4.160$ & 0.978 & 1.345 & $0.264-6.854$ & 0.721 \\
\hline \multicolumn{8}{|c|}{ Number of metastasis } \\
\hline 1 & 8 & 1 & & & 1 & & \\
\hline 2 & 2 & 3.369 & $0.658-17.237$ & 0.145 & 3.609 & $0.592-22.011$ & 0.164 \\
\hline \multicolumn{8}{|c|}{ Maximum size of the metastatic tumor } \\
\hline$<3 \mathrm{~cm}$ & 6 & 1 & & & 1 & & \\
\hline$\geqq 3 \mathrm{~cm}$ & 4 & 0.834 & $0.912-3.626$ & 0.809 & 0.831 & $0.201-3.635$ & 0.831 \\
\hline \multicolumn{8}{|l|}{ Hepatic surgery } \\
\hline Once & 8 & 1 & & & 1 & & \\
\hline Twice & 2 & 2.002 & $0.362-11.073$ & 0.426 & 1.453 & $0.280-7.549$ & 0.657 \\
\hline
\end{tabular}

cancer have not increased as much as those observed with hepatic resection for metastatic lesions of colon cancer [12-14]. Liver metastasis is an important point of consideration in treatment regimens for patients with gastric cancer $[16,17]$. Compared with colon cancer, fewer patients with gastric cancer are candidates for hepatic resection as they often harbor multiple liver metastases as well as coexisting metastases in other locations.

Several recent studies on liver resection in gastric cancer reported that some patients achieved long-term survival of $2-$
6 years, with 1- and 5-year OS rates of $60-77 \%$ and $10-42 \%$, respectively, and a median survival time ranging from 8.8 to 34 months; the findings of the current study are in agreement with these previous reports [1-11].

Among many studies investigating prognostic factors for liver resection in gastric cancer, several reported that single liver metastases and those measuring $<5 \mathrm{~cm}$ were associated with good prognosis $[2-5,9]$. However, in the present study, the number of liver metastases and tumor were not associated with OS. Patients with single liver metastatic lesions died within a 
year, and there was only one patient whose tumor diameter was $5 \mathrm{~cm}$. The patients in the present study were stratified according to a tumor diameter of $3 \mathrm{~cm}$. Further analysis using a tumor diameter cutoff value of $4 \mathrm{~cm}$ did not reveal significant differences in OS rates between the groups (data not shown).

Our results suggest that primary gastric cancer invading deeper than submucosa may be a poor prognostic factor. Serosal invasion is a proposed mechanism of peritoneal seeding [15], and some studies suggest that serosal invasion may be a poor prognostic factor for liver surgery $[8,10]$. In the present study, there were two patients with primary gastric cancers that were not deeper than submucosa who survived for 33 and 39 months, respectively. Of the remaining eight patients, six $(75 \%)$ died within 3 years of hepatic resection. The depth of primary gastric cancer should be considered as a prognostic factor in liver metastasis of primary gastric cancer.

Although several prognostic factors were reported to be associated with liver metastasis of primary gastric cancer, the size of primary gastric cancer was not previously reported as a significant predictor of favorable outcomes, which should be evaluated in future studies.

In the current study, two of the 10 patients underwent hepatic resection twice, and both survived for $>2$ years after the first hepatic resection, longer than the reported survival time. Surgery should be considered with consideration of the patient's clinical condition for recurrent liver metastasis following the first hepatic resection in patients with gastric cancer.

One major limitation of the present study is its retrospective design that involved a single institution; therefore, the number of patients was small, and only univariate analysis was performed. However, our cohort is similar to most studies on liver metastasis of gastric cancer which included a series of 10-20 patients at most, with a very limited number of larger cohorts available at this time. Despite the limited number of studies on hepatic resection of liver metastasis in gastric cancer, this approach was reported to be ineffective in certain patients. Therefore, future, large-scale studies are necessary to identify those patients who should undergo surgery.

\section{Conclusion}

Some of the patients undergoing hepatic resection for liver metastasis of gastric cancer achieved long-term survival. Primary tumor size was associated with long-term survival.

Acknowledgments The authors would like to thank Enago (www.enago. jp) for the English language review.

\section{Compliance with Ethical Standards}

Conflict of Interest The authors declare that they have no conflict of interest.
Ethical Approval All procedures performed in studies involving human participants were in accordance with the ethical standards of the institutional and/or national research committee and with the 1964 Helsinki declaration and its later amendments or comparable ethical standards.

For this type of study formal consent is not required.

Open Access This article is distributed under the terms of the Creative Commons Attribution 4.0 International License (http:// creativecommons.org/licenses/by/4.0/), which permits unrestricted use, distribution, and reproduction in any medium, provided you give appropriate credit to the original author(s) and the source, provide a link to the Creative Commons license, and indicate if changes were made.

\section{References}

1. Fujii K, Fujioka S, Kato K, Machiki Y, Kutsuna Y, Ishikawa A, Takamizawa J, Ko K, Yoshida K, Nimura Y (2001) Resection of liver metastasis from gastric adenocarcinoma. Hepatogastroenterology 48:368-371

2. Okano K, Maeba T, Ishimura K, Karasawa Y, Goda F, Wakabayashi H, Usuki H, Maeta H (2002) Hepatic resection for metastatic tumors from gastric Cancer. Ann Surg 235:86-91

3. Sakamoto Y, Ohyama S, Yamamoto J, Yamada K, Seki M, Ohta K, Kokudo N, Yamaguchi T, Muto T, Makuuchi M (2003) Surgical resection of liver metastases of gastric cancer: an analysis of a 17year experience with 22 patients. Surgery 133:507-511

4. Roh HR, Suh KS, Lee HJ, Yang HK, Choe KJ, Lee KU (2005) Outcome of hepatic resection for metastatic gastric cancer. Am Surg 71:95-99

5. Cheon SH, Rha SY, Jeung HC, Im CK, Kim SH, Kim HR, Ahn JB, Roh JK, Noh SH, Chung HC (2008) Survival benefit of combined curative resection of the stomach (D2 resection) and liver in gastric cancer patients with liver metastases. Ann Oncol 19:1146-1153

6. Fujisaki S, Tomita R, Nezu T, Kimizuka K, Park E, Fukuzawa M (2001) Prognostic studies on gastric cancer with concomitant liver metastases. Hepatogastroenterology 48:892-894

7. Zacherl J, Zacherl M, Scheuba C, Steininger R, Wenzl E, Muhlbacher F, Jakesz R, Langle F (2002) Analysis of hepatic resection of metastasis originating from gastric adenocarcinoma. $\mathrm{J}$ Gastrointest Surg 6:682-689

8. Koga R, Yamamoto J, Ohyama S, Saiura A, Seki M, Seto Y, Yamaguchi T (2007) Liver resection for metastatic gastric cancer: experience with 42 patients including eight long-term survivors. Jpn J Clin Oncol 37:836-842

9. Oki E, Tokunaga S, Emi Y, Kusumoto T, Yamamoto M, Fukuzawa K, Takahashi I, Ishigami S, Tsuji A, Higashi H, Nakamura T, Saeki H, Shirabe K, Kakeji Y, Sakai K, Baba H, Nishimaki T, Natsugoe S, Maehara Y (2016) Surgical treatment of liver metastasis of gastric cancer: a retrospective multicenter cohort study (KSCC1302). Gastric Cancer 19:968-976

10. Ochiai T, Sasako M, Mizuno S, Kinoshita T, Takayama T, Kosuge T, Yamazaki S, Maruyama K (1994) Hepatic resection for metastatic tumours from gastric cancer: analysis of prognostic factors. Br J Surg 81:1175-1178

11. Ambiru S, Miyazaki M, Ito H, Nakagawa K, Shimizu H, Yoshidome H, Shimizu Y, Nakajima N (2001) Benefits and limits of hepatic resection for gastric metastases. Am J Surg 18:279-283

12. H1 T, Takahashi T, Sawai K, Yamaguchi T, Hagiwara A, Kitamura K, Hoshima M, Masuyama M, Mugitani T, Takada A, Yamaguchi A (1997) Comparison in survival between hepatic metastases of gastric and colorectal cancers. Hepatogastroenterology 44:897-900

13. Imamura H, Matsuyama Y, Shimada R, Kubota M, Nakayama A, Kobayashi A, Kitamura H, Ikegami T, Miyagawa SI, Kawasaki S 
(2001) A study of factors influencing prognosis after resection of hepatic metastases from colorectal and gastric carcinoma. Am J Gastroenterol 96:3178-3184

14. Minagawa M, Makuuchi M, Torzilli G, Takayama T, Kawasaki S, Kosuge T, Yamamoto J, Imamura H (2000) Extension of the frontiers of surgical indications in the treatment of liver metastases from colorectal cancer: long-term results. Ann Surg 231:487-499

15. Maehara Y, Hasuda S, Koga T, Tokunaga E, Kakeji Y, Sugimachi K (2000) Postoperative outcome and sites of recurrence in patients following curative resection of gastric cancer. Br J Surg 87:353-357
16. Maruyama K, Okabayashi K, Kinoshita T (1987) Progress in gastric cancer surgery in Japan and its limits of radicality. World J Surg $11: 418-425$

17. Kaibara N, Sumi K, Yonekawa M, Ohta M, Makino M, Kimura O, Nishidoi H, Koga S (1990) Does extensive dissection of lymph nodes improve the results of surgical treatment of gastric cancer? Am J Surg 159:218-221 